of only one type of hand dexterity test, and the unknown efficacy of the distraction technique that was chosen. It is possible that some employees with multiple needlestick injuries and impaired hand function may have dedined to participate for fear that the data obtained might adversely affect their employment status despite assurances of confidentiality.

The Occupational Safety and Health Administration (OSHA) has placed an increasing responsibility on the employer to provide a safe working environment for the employee. While the provision of hepatitis B vaccine to all employees at risk can reduce the incidence of this important disease, other diseases such as HIV infection can be prevented only by reducing the rate of needlestick injuries. Although Universal Precautions have been advocated while handling all blood and body fluids, these measures do not appear to have reduced the frequency of needlestick injuries. Much information is lacking in regard to the reasons and remedies for this growing occupational problem. The present study indicates that repetitive needlestick inju- ries are not explained by intrinsic deficits of hand dexterity in certain healthcare personnel.

\section{REFERENCES}

1. De Laune S. Risk reduction through testing, screening and infection control precautions with special emphasis on needlestick injuries. Infect Control Hosp Epidemiol 1990;11(suppl):563565.

2. Heald AE, Ransohoff DE Needlestick injuries among resident physicians. J Gen Intern Med 1990;5:389-393.

3. American Medical Association. Patterns appearing in how, why needlesticks occur. American Medical News May 4, 1992:35.

4. Purdue Pegboard Instruction Manual. Lafayette, Indiana. Lafayette Instrument Company.

5. Jones E, Hanly JG, Mooney R, et al. Strength and function in the normal and rheumatoid hand. I Rheumatol 1991;18:1313-1318.

6. Casanova JE, Casanova JS, Young MJ. Hand function in patients with diabetes mellitus. South Med J 1991;84:1111-1113.

7. Squire D, Giachino AA, Profitt AW, Heaney C. Objective comparison of manual dexterity in physicians and surgeons. Can J Surg 1989;32:367-370.

8. Young MJ, Bresnitz EA, Strom BL. Sample size nomograms for interpreting negative clinical studies. Ann Intern Med 1983;99:248251.

\title{
Two New Videotapes on Tuberculosis Prevention
}

by Gina Pugliese, RN, MS

Medical News Editor

The Association for Practitioners in Infection Control (APIC) has released a new videotape, "Tuberculosis: Protection for Healthcare Workers." This 20minute educational videotape addresses the components of a comprehensive training program, including epidemiology, pathogenesis, transmission, prevention, skin testing, laboratory identification, environmental controls, treatment, personal protection, and medical monitoring. A comprehensive training packet designed to help ICPs implement the most recent CDC recommendations accompanies the video. For additional information, contact Lincoln Medical Education Foundation, Attention: APIC TB Video, 4600 Valley Rd., Lincoln NE 68510. Telephone (402) 4834581. FAX (402) 483- 4184.

Medcom/Trainex has released a video program entitled "Tuberculosis: Prevention and Practices for Healthcare Work- ers." The 22-minute videotape and 32-page study guide review TB symptoms, the difference between TB infection and disease, transmission, persons at risk, multidrug-resistant TB, complications of diagnosing TB in patients with HIV infection, preventive measures, and the $\mathrm{CDC}$ guidelines. For additional information, contact Medcom/Trainex, 12601 Industry St., Garden Grove, CA 92641. Telephone (800) 877- 1443. FAX (714) 8984852 . 